\title{
A Bibliography of Papers on Queueing Networks with \\ Finite Capacity Queues
}

Harry G. Perros

Center for Communications and Signal Processing Department of Electrical and Computer Engineering North Carolina State University

September 1989

TR-89/10 


\title{
A BIBLIOGRAPHY OF PAPERS ON \\ QUEUEING NETWORKS WITH FINITE CAPACITY QUEUES
}

\author{
by \\ H.G. Perros 1,2 \\ Computer Science Department \\ and \\ Center for Communications and Signal Processing \\ North Carolina State University \\ Raleigh, NC 27695-8206, USA
}

This list of references is an updated version of an earlier bibliography by Perros[153]. It contains published papers, technical reports, and Ph.D. theses, in which analytic (exact or approximate) and numerical studies of queueing networks with finite capacity queues have been reported. In general, it was difficult to establish the exact state of some of the technical reports. It is possible, therefore, that some of the technical reports listed in this bibliography have already been published with or without changes in their titles. Also, only these $\mathrm{Ph} . \mathrm{D}$. theses that have not been published as papers are referenced. Despite the effort to compile an exhaustive bibliography of the literature in this area, there is little doubt that a number of related papers have been omitted. It is only hoped that these unintentionally omitted papers represent a small percentage of all the relevant papers.

${ }^{1}$ Supported in part by the National Science Foundation under grant no CCR-87-02258.

${ }^{2}$ Photograph and biographical details of the author are given in the introduction of this special issue.

[1] I. Adan and J. van der Wal, Monotonicity of the throughput in single server production and assembly networks with respect to the buffer sizes, in: Perros and Altiok, eds., Proc. First International Workshop on Queueing Networks with Blocking, (North Holland, 1989) 345-356.

[2] I.F. Akyildiz, Exact product form solution for queueing networks with blocking, IEEE Trans. Comp. 36 (1987) 121-126.

[3] I.F. Akyildiz, Mean value analysis for blocking queueing networks, IEEE Trans. Soft. Eng. SE-14 (1988) 418-429. 
[4] I.F. Akyildiz, On the exact and approximate throughput analysis of closed queueing networks with blocking, IEEE Trans. Soft. Eng. SE-14 (1988) 62-71.

[5] I.F. Akyildiz, Performance analysis of computer and communication networks with local and global window flow control, INFOCOM 88, 400-410.

[6] I.F. Akyildiz, General closed queueing networks with blocking, in: Courtois and Latouche, eds., PERFORMANCE '87 (North Holland, 87) 283-303.

[7] I.F. Akyildiz, Exact analysis of queueing networks with rejection blocking, in:

Perros and Altiok, eds., Proc. First International Workshop on Queueing Networks with Blocking, (North Holland, 1989) 19-29.

[8] I.F. Akyildiz and J. Liebeherr, Application of Norton's theorem on queueing networks with finite capacities, INFOCOM 89 914-923.

[9] I.F. Akyildiz and H. von Brand, Exact solutions for open, closed and mixed queueing networks with rejection blocking, Theoretical Computer Science J. 64 (1989) 203-219.

[10] I.F. Akyildiz and H. von Brand, Computational algorithms for networks of queues with rejection blocking, to appear in Acta Informatica.

[11] I.F. Akyildiz, Product form approximations for queueing networks with multiple servers and blocking, IEEE Trans. Computers 38 (1989) 99-115.

[12 I.F. Akyildiz and H. von Brand, Central server models with multiple job classes, state dependent routing, and rejection blocking, to appear in IEEE Trans. Soft. Eng.

[13] I.F. Akyildiz and H. von Brand, Dual and self dual networks of queues with rejection blocking, to appear in Computing J.

[14] T. Altiok, Approximate analysis of exponential tandem queues with blocking, European J. Oper. Res. 11 (1982) 390-398.

[15] T. Altiok and S. Stidham, A note on transfer lines with unreliable machines, random processing times and finite buffers, IIE Trans. (1982) 125-127.

[16] T. Altiok and S. Stidham, The allocation of interstage buffer capacities in production lines, IIE Trans. 15 (1983) 292-299.

[17] T. Altiok, Production lines with phase type operations and repair times and finite buffers, Int. J. Prod. Res. 28 (1985) 489-498.

[18] T. Altiok and H.G. Perros, Open networks of queues with blocking: split and merge configurations, IIE Trans. (1986) 251-261.

[19] T. Altiok and H.G. Perros, Approximate analysis of arbitrary configurations of open queueing networks with blocking, Annals Oper. Res. 9 (1987) 481-509.

[20] T. Altiok, Approximate analysis of queues in series with phase-type service times and blocking, Oper. Res. 37 (1989)601-610. 
[21] T. Altiok and Z. Kao, Bounds for throughput in production/inventory systems in series with deterministic processing times, Industrial Engineering Rept., Rutgers Univ., 1987.

[22] T. Altiok and R. Ranjan, Analysis of production lines with general service times and finite buffers: a two-node decomposition approach, Industrial Engineering Rept., Rutgers Univ., 1987.

[23] T. Altiok and R. Ranjan, Multi-stage, pull-type production/inventory systems with set-ups and (R,r) control policies, Industrial Engineering Rept. 88-108, Rutgers Univ., 1988.

[24] M.H. Ammar and S.B. Gershwin, Equivalence relation in queueing models of manufacturing networks, in: Proc. IEEE Conf. on Decision and Control, Albuquerque, 1980.

[25] G.T. Artamonov, Productivity of a two-instrument discrete processing line in the presence of failures, Kibernetica 3 (1976) 126-130 (English tr. Cybernetics 12 (1977) 464-468).

[26] B. Asare, Queue networks with blocking, Ph.D. Thesis, Trinity College Dublin, Ireland, 1978.

[27] B. Avi-Itzhak and M. Yadin, A sequence of two servers with no intermediate queue, Mgmt. Sci. 11 (1965) 565-571.

[28] B. Avi-Itzhak, A sequence of service stations with arbitrary input and regular service times, Mgmt. Sci. 11 (1965) 565-571.

[29] S. Balsamo and G. Iazeolla, Some equivalence properties for queueing networks with and without blocking, in: Agrawala and Tripathi, eds., Performance '83 (North-Holland, 1983) 351-360.

[30] S. Balsamo and L. Donatiello, On the cycle time distribution in a two-stage cyclic network with blocking, Proc. of Fourth Int. Conf. on Modelling Techniques and Tools for Computer Performance Evaluation, Palma de Mallorca, 1988, 513-528.

[31] P.C. Bell, The use of decomposition techniques for the analysis of open restricted queueing networks, Oper. Res. Letters 1 (1982) 230-235.

[32] P.P. Bocharov and F.K. Albores, On two-stage exponential queueing system with internal losses or blocking, Problems of Control and Information Theory 9 (1980) 365-379.

[33] P.P.Bocharov and G.P Rokhas, On an exponential queueing system in series with blocking, Problems of Control and Information Theory 9 (1980) 441-455.

[34] P.P. Bocharov and S.S. Spesivov, On multistage queueing system with losses and arriving flow of phase type, Problems of Control and Information Theory 15 (1986) 465-474.

[35] P.P.Bocharov, On the two-node queueing networks with finite capacity, in: Perros and Altiok, eds., Proc. First International Workshop on Queueing Networks with Blocking, (North Holland, 1989) 105-125. 
[36] O. Boxma and A. Konheim, Approximate analysis of exponential queueing system with blocking, Acta Informatica 15 (1981) 19-66.

[37] A. Brandwajn and Y.-L.L. Jow, An approximation method for tandem queues with blocking, Oper. Res. 36 (1988) 73-83.

[38] A. Brandwajn and Y.-L.L. Jow, Tandem exponential queues with finite buffers, in: Proc. Int. Seminar on Computer Networking and Performance Evaluation, Tokyo, Sept 18-20, 1985.

[39] J.A. Buzacott, Automatic transfer lines with buffer stocks, Int. J. Prod. Res. 5 (1967) 183-200.

[40] J.A. Buzacott, The effect of station breakdowns and random processing times on the capacity of flow lines with in-process storage, AIIE Trans. 4 (1972) 308-312.

[41] J.A. Buzacott and L.E. Hanifin, Models of automatic transfer lines with inventory banks - a review and comparison, AIIE Trans. 10 (1978) 197-207.

[42] P. Caseau and G. Pujolle, Throughput capacity of a sequence of queues with blocking due to finite waiting room, IEEE Trans. Soft. Eng. SE-5 (1979) 631-642.

[43] S. Chakravarthy, Analysis of production line systems with two unreliable machines with phase-type processing times and a finite storage buffer, Science and Mathematics Rept, GMI Engineering and Management Institute, 1986.

[44] Q.H. Choo and B. Conolly, Waiting time analysis for a tandem queue with correlated service, European J. Oper. Res. 4 (1980) 337-345.

[45] Y.F. Choong and S.B. Gershwin, A decomposition method for the approximate evaluation of capacitated transfer lines with unreliable machines and random processing times, IIE trans. 19 (1985) 150-159.

[46] A.B. Clarke, Markovian queues with servers in tandem, Mathematics Rept. 49, Western Michigan Univ., 1977.

[47] A.B. Clarke, A two-server tandem queueing system with storage between servers, Mathematics Rept. 50, Western Michigan Univ., 1977.

[48] A.B. Clarke, A multiserver general service time queue with servers in series, Mathematics Rept. 51, Western Michigan Univ., 1978.

[49] A.B. Clarke, Waiting times for Markovian queue with servers in series, Mathematics Rept. 52, Western Michigan Univ., 1978.

[50] M. Choi, Multiclass queueing networks with finite buffers, Ph.D. Thesis, University of North Carolina State University (1989).

[51] J.W. Cohen, The multiple phase service network with generalized processor sharing, Acta Informatica 12 (1979) 245-284. 
[52] Y. Dallery and D.D. Yao, Modelling of flexible manufacturing cells, in: Kusiak (ed.) Modelling and Design of Flexible Manufacturing Systems, (North-Holland, 1986) $289-300$.

[53] Y. Dallery, R. David, and X.-L. Xie, An efficient algorithm for analysis of transfer lines with unreliable machines and finite buffers, IEE 20 (1988) 280-283.

[54] Y. Dallery, R. David, and X.-L. Xie, Approximate analysis of transfer lines with unreliable machines and finite buffers, Lab. d'Automatic de Grenoble Rept. 8764, 1987.

[55] Y. Dallery and Y. Frein, A decomposition method for the approximate analysis of closed queueing networks with blocking, in: Perros and Altiok, eds., Proc. First International Workshop on Queueing Networks with Blocking, (North Holland, 1989) $193-215$.

[56] Dattatreya, E.S., Tandem queueing systems with blocking, Ph.D. Thesis, University of California, Berkeley, 1978.

[57] S. Daskalaki and J. MacGregor Smith, The static routing problem in open finite queueing networks, in: Perros and Altiok, eds., Proc First Int. Workshop on Queueing Networks with blocking (North Holland, 1989) 313-324.

[58] R.V. Evans, Capacity of queueing networks, Oper. Res. 15 (1967) 530-536.

[59] R.V. Evans, Geometric distributions in some two-dimensional queueing systems, Oper. Res. 15 (1967) 830-846.

[60] F.G. Foster and H.G. Perros, Hierarchical queue networks with partially shared servicing, J. Opl. Res. Soc. 30 (1979) 157-166.

[61] F.G. Foster and H.G. Perros, On the blocking process in queue networks, European J. Oper. Res. 5 (1980) 276-283.

[62] F.G. Foster and H.G. Perros, On the blocking process in queue networks, European J. Oper. Res. 5 (1980) 276-283.

[63] S.B. Gershwin and O. Berman, Analysis of transfer lines consisting of two unreliable machines with random processing times and finite storage buffers, AIIE Trans. 13 (1981) 2-11.

[64] S.B. Gershwin and I.C. Shick, Modelling and analysis of three-stage transfer lines with unreliable machines and finite buffers, Oper. Res 31 (1983) 354-380.

[65] S.B. Gershwin, An efficient decomposition method for the approximate evaluation of tandem queues with finite storage space and blocking, Oper. Res. 35 (1987) 291-305.

[66] S.B. Gershwin, Representation and analysis of transfer lines with machines that have different processing rates, Annals Oper. Res. 8 (1987) 511-530.

[67] S.B. Gershwin, An efficient decomposition algorithm for unreliable tandem queueing systems with finite buffers, in: Perros and Altiok, eds., Proc First Int. Workshop on Queueing Networks with blocking (North Holland, 1989) 127-146. 
[68] W.J. Gordon and G.F. Newell, Cyclic queueing systems with restricted length queues, Oper. Res. 15 (1967) 266-278.

[69] K. Goto, Y. Takahashi, and T. Hasegawa, An approximate analysis of controlled tandem queues, in: Proc. Conference on Modelling and Performance Evaluation, (Springer-Verlag, vol 60, 1983)601-612.

[70] L. Gün and A.M. Makowski, Matrix-geometric solution for finite queues with phase-type distribution, in: Courtois and Latouche, eds., Performance ' 87 (NorthHolland, 1988) 269-282.

[71] L. Gün and A.M. Makowski, An approximation method for general tandem queueing systems subject to blocking, in Perros and Altiok, eds.,Proc. First International Workshop on Queueing Networks with Blocking, (North Holland, 1989) $147-171$.

[72] L. Gün Annotated bibliography of blocking systems, Tech. Rept. Electr. Eng. Dept., Univ. of Maryland, 1987.

[73] J.M. Hatcher, The effect of internal storage on the production rate of a series of stages having exponential service times, AIIE Trans. 1 (1969) 150-156. (See also: Letter to the above article by A.D. Knott, AIIE Trans. (1970) 273.)

[74] D.K. Hildebrand, Stability of finite queue, tandem server systems, J. Appl. Prob. 4 (1967) 571-583.

[75] D.K. Hildebrand, On the capacity of tandem server, finite queue, service systems, Oper. Res. 16 (1968) 72-82.

[76] F.S. Hillier and R.W. Boling, Finite queues in series with exponential or Erlang service times - a numerical approach, Oper. Res. 15 (1967) 286-303.

[77] A. Hordijk and N. van Dijk, Networks of queues with blocking, in: Kylstra, ed.,Performance ' 81 (North Holland, 1981) 51-65.

[78] A. Hordijk and N. van Dijk, Adjoint processes, job-local-balance and insensitivity of stochastic networks, Bull 44th Session Int. Stat. Inst. 50 (1982) 776-788.

[79] A. Hordijk and N. van Dijk, Networks of queues, Part I: Job-local balance and the adjoint process; Part II: General routing and service characteristics, in: Proc. Intern. Conf. on Modelling for Computer Systems (Springer, 1983) 158-205.

[80] G.C. Hunt, Sequential arrays of waiting lines, Oper. Res. 4 (1956) 674-683.

[81] E. Ignall and A. Silver, The output of a two-stage system with unreliable machines and limited storage, AIIE Trans. 9 (1977) 183-188.

[82] M.A. Jafari and J.G. Shanthikumar, Allocation of buffer storages along a multistage automatic transfer line, Industrial Engineering Rept. 84-003, Arizona University, 1984. 
[83] M.A. Jafari and J.G. Shanthikumar, A model of two-stage flow lines with nongeometric uptimes and downtimes and possible scrapping of workpieces, Industrial Engineering and Operations Research Rept.85-008, Syracuse University, 1985.

[84] M.A. Jafari and J.G. Shanthikumar, Determination of optimal buffer storage capacities and optimal allocation in multistage automatic transfer lines, Industrial Engineering and Operations Research Rept.85-011, Syracuse University, 1985

[85] M.A. Jafari and J.G. Shanthikumar, Finite state spatially non-homogeneous quasibirth-and-death-process, Industrial Engineering and Operations Research Rept. 85008, Syracuse University, 1985.

[86] A.R. Jassim, An M/G/1 queueing node with finite storage space and possibly blocked departure, CSR Rept., City university, 1987.

[87] A.R. Jassim, Performance modelling of finite storage double loop fault tolerant ring network, CSR Rept., City University, 1987.

[88] K.-P. Jun and H.G. Perros, An approximate analysis of open tandem queueing networks with blocking and general service times, to appear in Euro. J. Oper. Res.

[89] K.-P. Jun and H.G. Perros, Approximate analysis of arbitrary configurations of queueing networks with blocking, in: Perros and Altiok, eds., Proc. First International Workshop on Queueing Networks with Blocking, (North Holland, 1989) 259-280.

[90] F.P. Kelly, Reversibility and stochastic networks, Wiley, 1979.

[91] F.P. Kelly, The throughput of a series of buffers, Adv. Appl. Prob. 14 (1982) 633-653.

[92] F.P. Kelly, Blocking, reordering, and the throughput of a series of servers, Stochastic Processes and their Applications 17 (1984) 327-336.

[93] L. Kerbache and J. MacGregor Smith, The generalized expansion method for open finite queueing networks, European J. Oper. Res. 32 (1987) 448-461.

[94] A.D. Knott, The inefficiency of a series of work stations - a simple formula, Int. J. Prod. Res. 8 (1970) 109-119.

[95] E. Koenigsberg, Production lines and internal storage - a review, Mgmt. Sci. 5 (1959) 410-433.

[96] Y.A. Kogan and E.V. Krichagina, Closed exponential queueing networks with blocking in heavy traffic, in: Perros and Altiok, eds., Proc. First International Workshop on Queueing Networks with Blocking, (North Holland, 1989) 217226.

[97] Y.A. Kogan and A. Pukhalskii, On tandem queues with blocking in heavy traffic, in: Gelenbe (Ed.) PERFORMANCE' 84 (North-Holland, 1984) 549-558.

[98] A.G. Konheim and M. Reiser, A queueing model with finite waiting room and blocking, J.ACM 23 (1976) 328-341. 
[99] A.G. Konheim and M. Reiser, Finite capacity queueing systems with applications in computer modelling, SIAM J. Computing 7 (1978) 210-229.

[100] R. de Koster, Capacity analysis of two-stage production lines with many products, Eng. Costs and Prod. Econ. 12 (1987) 175-186.

[101] R. de Koster, Estimation of line efficiency by aggregation, Int. J. Prod. Res. 25 (1987) 615-626.

[102] R. de Koster, and J. Wijngaard, On the use of continuous vs discrete models in production lines with buffers, in Perros and Altiok, eds., Proc. First Int. Workshop on Queueing Networks with Blocking (North-Holland, 1989) 175-191.

[103] R. de Koster, Approximation of flow lines with integrally controlled buffers, to appear in IIE Trans.

[104] R. de Koster, Approximate analysis of production systems, to appear in European J. Oper. Res.

[105] R. de Koster, and J. Wijngaard, Local and integral control of workload, to appear in Int. J. Prod. Res.

[106] R. de Koster, and J. Wijngaard, A continuous flow model for three production units in series with buffers, Operations Research Proceedings 1985 (SpringerVerlag, 1986) 253-264.

[107] D. Kouvatsos and J. Almond, Maximum entropy two-station cyclic queues with blocking, Computer Science Rept.DDK/JA-1, Univ. of Bradford.

[108] D. Kouvatsos and N.P. Xenios, Maximum entropy analysis of general queueing networks with blocking, in: Perros and Altiok, eds.,Proc. First International Workshop on Queueing Networks with Blocking, (North Holland, 1989) 281309.

[109] C. Krishna and K. Shin, Queueing analysis of a canonical model of real-time multiprocessors, in: Bruell and Dowdy, eds., Proc. ACM SIGMETRICS Conference on Measurement and Modelling of Computer Systems , (1983) 175189.

[110] A. Krzesinski, Approximate solution methods for multiclass queueing networks with state-dependent routing and blocking, Tech. Rept., Univ. of Stellenbosch, 1987.

[111] S. Kundu and I.F. Akyildiz, Deadlock free buffer allocation in closed queueing networks, Queueing Systems J. 4 (1989) 47-56.

[112] J. Labarta, J. Domingo, and O. Casals, Performance evaluation of packet switched omega networks with finite buffers, in: Perros and Altiok, eds., Proc. First International Workshop on Queueing Networks with Blocking, (North Holland, 1989) 249-255.

[113] J. Labetoulle and G. Pujolle, Modelling of packet switching communication networks with finite buffer size at each node, in: Chandy and Reiser, eds., Computer Performance (North Holland, 1977) 515-535. 
[114] J. Labetoulle and G. Pujolle, Isolation method in a network of queues, IEEE Trans. Soft. Eng. SE-6 (1980) 373-381.

[115] J. Labetoulle and G. Pujolle, A study of queueing networks with deterministic service and applications to computer networks, Acta Informatica 7 (1976) 183195.

[116] C. Langaris and B. Conolly, On the waiting time of a two-stage queueing system with blocking, J. Appl. Prob. 21 (1984) 628-638.

[117] C. Langaris and B. Conolly, Two queues in tandem with multiple facilities and restricted waiting space, METRON, XLIII (1985).

[118] C. Langaris and B. Conolly, Three stage tandem queue with blocking, European J. Oper. Res 19 (1985) 222-232.

[119] G. Latouche and M.F. Neuts, Efficient algorithmic solutions to exponential tandem queues with blocking, SIAM J. of Alg. Disc. Meth. 1 (1980) 93-106.

[120] S.S. Lavenberg, Stability and maximum departure rate of certain open queueing networks having finite capacity constraints, RAIRO Informatique/Computer Science 12 (1978) 353-370.

[121] A.A. Lazar and T.G. Robertazzi, The geometry of lattices for Markovian queueing networks, Electrical Engineering Rept., Columbia Univ., 1984.

[122] H.-S. Lee and S.M. Pollock, Approximate analysis of open exponential queueing networks with blocking: general configuration, to appear in Oper. Res.

[123] L.-M. Le Ny, Forme produit pour des reseaux multiclasses à routage dynamique, Annales Scientifiques de l'Universitè de Clermont-Ferrand II 76 (1983) 17-34.

[124] L.-M. Le Ny, Étude analytique de reseaux de files d'attende multiclasses à routage variable, RAIRO Recherche Operationnelle 14 (1980) 331-347.

[125] X.-G. Liu and J.A. Buzacott, A balanced local flow technique for queueing networks with blocking, in: Perros and Altiok, eds., Proc. First International Workshop on Queueing Networks with Blocking, (North Holland, 1989) 87-104.

[126] J. MacGregor and S. Daskalaki, Buffer space allocation in automated assembly lines, Oper. Res. 36 (1988) 343-358.

[127] T. Makino, On the mean passage time concerning some queueing problems of the tandem type, J. Oper. Res. Soc. Japan 7 (1964) 17-47.

[128] W.A. Massey, Balanced queues in series with communication blocking, to appear in Math. of Oper. Res.

[129] B. Melamed, A note on the reversibility and duality of some tandem blocking queueing systems, Mgmt. Sci. 32 (1986) 1648-1650.

[130] D. Mitra and I. Mitrani, Control and coordination policies for systems with buffers, Proc. ACM SIGMETRICS and PERFORMANCE '89, 156-164. 
[131] D. Mitra and I. Mitrani, Analysis of a novel discipline for cell coordination in production lines II, AT\&T Bell Lab Rept., 1988.

[132] E. Muth, The production rate of a series of work stations with variable service times, Int. J. Prod. Res. 11 (1973) 155-169.

[133] E.J. Muth, The reversibility property of production lines, Mgmt. Sci. 25 (1979) 152-158.

[134] E.J. Muth and S. Yeralan, Effect of buffer size on productivity of work stations that are subject to breakdowns, in: Proc. 20th IEEE Conf. on Decision and Control, (1981), 643-648.

[135] M.F. Neuts, Two-queues in series with a finite, intermediate waiting room, J. Appl. Prob. 5 (1968) 123-142.

[136] M.F. Neuts, Matrix-geometric solutions in stochastic models - an algorithmic approach, (The John Hopkins Univ. Press, 1981) 232-245.

[137] G. F. Newell, Approximate behavior of tandem queues, Lecture Notes in Economics and Mathematical Systems, 171 (Springer-Verlag, 1979).

[138] A. Nilsson and T. Altiok, Open queueing networks with finite capacity queues, in: Proc. 1981 Int. Conf. Parallel Processing, (1981), 87-91.

[139] T. Ohmi, An approximation for the production efficiency of automated transfer lines with in-process storage, AIIE Trans. 13 (1981) 22-28.

[140] K. Okamura and H. Yamashina, Analysis of the effect of buffer storage capacity in transfer line systems, AIIE Trans. 9 (1977) 127-135.

[141] R.O. Onvural and H.G. Perros, On equivalencies of blocking mechanisms in queueing networks with blocking, Oper. Res. Letters 5 ( 1986) 293-297.

[142] R.O. Onvural, H.G. Perros, and T. Altiok, On the complexity of the matrixgeometric solution of exponential open queueing networks with blocking, in: Pujolle, Fdida, and Horlait, eds., Proc. Int. Workshop on Modelling Techniques and Performance Evaluation (North Holland, 1987) 3-12.

[143] R.O. Onvural and H.G. Perros, Throughput analysis of cyclic queueing networks with finite buffers, IEEE Trans. Soft. Eng. SE-15 (1989) 800-808.

[144] R.O. Onvural and H.G. Perros, Some equivalencies between closed queueing networks with blocking, Performance Evaluation J. 9 (1989) 111-118.

[145] R. Onvural, On the exact decomposition of closed queueing networks with finite buffers, in: Perros and Altiok, eds., Proc. First International Workshop on Queueing Networks with Blocking, (North Holland, 1989) 73-83.

[146] R.O. Onvural and H.G. Perros, Equivalencies between open and closed queueing networks with finite buffers, Proc. Int. Seminar Performance of Distributed and Parallel Systems, Dec. 7-9, 1988, Kyoto, Japan. 
[147] R.O. Onvural, A survey of closed queueing networks with finite buffers, to appear in ACM Computing Surveys. (A version of this paper will also appear in: Takagi (Ed.) Stochastic Analysis of Computer and Communication Systems (NorthHolland).

[148] H.T. Papadopoulos and M.E.J. O'Kelly, Exact analysis of production lines, Industrial Engineering Rept., University College, Galway, 1988.

[149] R.L. Patterson, Markov processes occurring in the theory of traffic flow through an N-stage stochastic service system, J. Ind. Eng. 14 (1964) 188-193.

[150] J. Pellaumail and P. Boyer, Deux files d'attente à capacité limitée en tandem, CNRS/INRIA - Rennes Rept. 147, 1981.

[151] H.G. Perros, A symmetrical exponential open queue network with blocking and feedback, IEEE Trans. Soft. Eng. SE-7 (1981) 395-402.

[152] H.G. Perros, A two-level open queue network with blocking and feedback, RAIRO Recherche Operationnelle/Oper. Res. 15 (1981) 27-38.

[153] H.G. Perros, Queueing networks with blocking: a bibliography, Perf. Eval. Review 12 (1984) 8-12.

[154] H.G. Perros and T. Altiok, Approximate analysis of open networks of queues with blocking: tandem configurations, IEEE Trans. Soft. Eng. SE-12 (1986) 450-461.

[155] H.G. Perros, A survey of two-node queueing networks with blocking, Computer Science Rept., North Carolina State University, 1988.

[156] H.G. Perros, A.A. Nilsson and Y.-C. Liu, Approximate analysis of product-form type queueing networks with blocking and deadlock, Performance Evaluation 8 (1988) 19-39.

[157] H.G. Perros and P.M. Snyder, A computationally efficient approximation algorithm for analyzing queueing networks with blocking, Performance Evaluation J. 9 (1988/89) 217-224.

[158] H.G. Perros, Approximation algorithms for open queueing networks with blocking, to appear in Takagi (Ed.) Stochastic Analysis of Computer and Communication Systems (North-Holland).

[159] V.D.N. Personè and D. Grillo, Managing blocking in finite capacity symmetrical ring networks, in: Moraes, de Souza e Silva, and Soares, eds., Proc. of 3 rd Int. Conf. on Data Communication Systems and their Performance, Rio de Janeiro, $1987,225-240$.

[160] M. Pinedo and R.W. Wolf, A comparison between tandem queues with dependent and independent service times, Oper. Res. 30 (1982) 464-479.

[161] B. Pittel, Closed exponential networks of queues with saturation: The Jackson-type stationary distribution and its asymptotic analysis, Math. Oper. Res. 4 (1979) 367 378. 
[162] S.M. Pollock, J.R. Birge, and J.M. Alden, Approximation analysis for open tandem queues with blocking: exponential and general distributions, IOE Rept. 8530, Univ. of Michigan, 1985.

[163] N.U. Prabhu, Transient behavior of a tandem queue, Mgmt. Sci. 13 (1967) 631639.

[164] G. Pujolle and D. Potier, Reseaux de files d'attente à capacité limitée avec des applications aux systemes informatiques, RAIRO Informatique/Computer Science 13 (1979) 175-197.

[165] N.P. Rao, On the mean production rate of a two-stage production system of the tandem type, Int. J. Prod. Res. 13 (1975) 207-217.

[166] N.P. Rao, Two-stage production systems with intermediate storage, AIIE Trans. 7 (1975) 414-421.

[167] K. Rege, Approximate analysis of serial manufacturing lines with buffer control, to appear in Large Scale Systems J.

[168] P.J. Schweitzer and T. Altiok, Aggregate modelling of tandem queues with intermediate buffers, in: Perros and Altiok, eds., Proc. First International Workshop on Queueing Networks with Blocking, (North Holland, 1989) 19-29.

[169] B.A. Sevast'yanov, Influence of storage bin capacity on the average standstill time of a production line, Teoriya Veroyatnostey i ee Primeneniya 7 (1962) 429-438 (English translation Theory of Probability and its Applications 7 (1962) 429-438).

[170] J.G. Shanthikumar and M.A. Jafari, Bounding the performance of tandem queues with finite buffer spaces, Industrial Engineering Rept. Rutgers University, 1988.

[171] J.G. Shanthikumar and D.D. Yao, Monotonicity properties in cyclic queueing networks with finite buffers, in: Perros and Altiok, eds., Proc. First International Workshop on Queueing Networks with Blocking, (North Holland, 1989) 325344.

[172] T.J. Sheskin, Allocation of interstage storage along an automatic production line, AIIE Trans. 8 (1976) 146-152.

[173] A.I. Soyster and D.I. Toof, Some comparative and design aspects of fixed cycle production systems, Naval Research Logistics Quarterly 23 (1976) 437-454.

[174] A.L. Soyster, J.W. Schmidt, and M.W. Rohrer, Allocation of buffer capacities for a class of fixed cycle production lines, AIIE Trans. 11 (1979) 140-146.

[175] W.J. Stewart, Recursive procedures for the numerical solution of Markov chains, in: Perros and Altiok, eds., Proc. First International Workshop on Queueing Networks with Blocking, (North Holland, 1989) 229-247.

[176] R. Suri and G.W. Diehl, A new building block for performance evaluation of queueing networks with finite buffers, Proc. ACM SIGMETRICS on Measurement and Modelling of Computer Systems, (1984) 134-142. 
[177] R. Suri and G.W. Diehl, A variable buffer-size model and its use in analyzing closed queueing networks with blocking, Mgmt. Sci. 32 (1986) 206-224.

[178] T. Suzuki, On a tandem queue with blocking, J. Oper. Res. Soc. Japan 6 (1964) 137-157.

[179] Y. Takahashi, H. Miyahara and T. Hasegawa, An approximation method for open restricted queueing networks, Oper. Res. 28 (1980) 594-602.

[180] Y. Takahashi, Aggregate approximation for acyclic queueing networks with communication blocking, in: Perros and Altiok, eds., Proc. First International Workshop on Queueing Networks with Blocking, (North Holland, 1989) 33-46.

[181] G.D. Tsiotras, Exact and approximate analysis of queueing network models with blocking, Ph.D. Thesis, State University of New York at Stony Brook, 1987.

[182] P. Tsoucas and J. Walrand, Monotonicity of throughput in non-Markovian networks, to appear in J. Appl. Prob.

[183] N.M. van Dijk and H.G. Tijms, Insensitivity in two node blocking models with applications, in: Boxma and Cohen (Eds.) Teletraffic analysis and Computer Performance Evaluation (North-Holland, 1986)

[184] N. van Dijk, A simple bounding methodology for non-product -form finite capacity queueing networks, in: Perros and Altiok, eds., Proc. First International Workshop on Queueing Networks with Blocking, (North Holland, 1989) 3-17.

[185] N. van Dijk and B.F. Lamond, Bounds for the call congestion in tandem queues, to appear in Oper. Res.

[186] N. van Dijk and I.F. Akyildiz, Networks with mixed sharing parallel queues and common pools, Tech. Rept. Computer Science Dept. , Georgia Inst. of Tech., 1988.

[187] G. Yamazaki, T. Kawashima, and H. Sakasegawa, Reversibility of tandem blocking queueing systems, Mgmt. Sci. 31 (1985) 78-83.

[188] D.D. Yao and J.A. Buzacott, Modeling a class of state-dependent routing in flexible manufacturing systems, Annals Oper. Res. 3 (1985) 153-167.

[189] D.D. Yao and J.A. Buzacott, Queueing models for a flexible machining station part ii: the method of Coxian phases, European J. Oper. Res. 19 (1985) 241-252.

[190] D.D Yao and J.A. Buzacott, Modeling a class of flexible manufacturing systems with reversible routing, Oper. Res. 35 (1987) 87-93.

[191] D.D. Yao and J.A. Buzacott, The exponentialization approach to flexible manufacturing system models with general service times, European J. Oper. Res. 24 (1986) 410-416.

[192] E. Wesfreid, Dynamic behaviour of N-stage transfer lines with unreliable machines and finite buffers, INRIA Rept. 456, 1985. 
[193] J. Wijngaard, The effect of interstage buffer storage on the output of two unreliable production units in series with different production rates, AIIE Trans. 11 (1979) 42-47.

[194] B. Wong, W. Giffin and R. Disney, Two-finite $M / M / 1$ queues in tandem: a matrix solution for the steady state, Opsearch 14 (1977) 1-18. 